\title{
Monthly averaged ozone and nitrous oxide from the Improved Limb Atmospheric Spectrometer (ILAS) in the Northern and Southern Hemisphere polar regions
}

\author{
Farahnaz Khosrawi, ${ }^{1,2}$ Rolf Müller, ${ }^{3}$ Michael H. Proffitt, ${ }^{4}$ and Hideaki Nakajima ${ }^{1}$ \\ Received 18 November 2003; revised 25 February 2004; accepted 2 April 2004; published 19 May 2004.
}

[1] Northern and southern hemispheric averaged ozone $\left(\mathrm{O}_{3}\right)$ and nitrous oxide $\left(\mathrm{N}_{2} \mathrm{O}\right)$ measured by the Improved Limb Atmospheric Spectrometer (ILAS) were used to examine photochemical and dynamical changes in high-latitude $\mathrm{O}_{3}$ distributions. Using correlations of $\mathrm{O}_{3}$ versus $\mathrm{N}_{2} \mathrm{O}$, the ILAS data are organized monthly in both hemispheres by partitioning these data into equal bins of altitude or potential temperature. The resulting families of curves help to differentiate $\mathrm{O}_{3}$ changes due to photochemistry from those due to transport. Our study extends the work of Proffitt et al. [2003] for the Northern Hemisphere to the Southern Hemisphere. Further, our study confirms and extends their results for the Northern Hemisphere by applying their analysis to a significantly greater altitude range. As in the Northern Hemisphere, the families of curves for the altitude, and potential temperature bins in the Southern Hemisphere are separated and generally do not cross. In both hemispheres a better separation is found for the potential temperature binning. In the Southern Hemisphere November and December data, preserved photochemical $\mathrm{O}_{3}$ loss is evident in the lower stratosphere. Further, summer ozone loss is evident in the Southern Hemisphere from January to March. In the Arctic, ongoing photochemical $\mathrm{O}_{3}$ loss is evident in the Northern Hemisphere spring data. While at higher altitudes the correlation between $\mathrm{N}_{2} \mathrm{O}$ and $\mathrm{O}_{3}$ is generally positive (increasing $\mathrm{N}_{2} \mathrm{O}$ with increasing $\mathrm{O}_{3}$ ), at lower levels the correlation is negative. This change of correlation from positive to negative can be interpreted in terms of photochemical and dynamical processes. Strong descent causes a steepening of the positively correlated curves, while the curves change their slope from positive to negative if photochemical destruction of $\mathrm{O}_{3}$ is present and descent is weak. The level of slope change is also photochemically influenced and therefore changes with season. Data sets such as the one derived here may be useful for testing atmospheric models and for identifying future changes in stratospheric ozone. INDEX TERMS: 0340 Atmospheric Composition and Structure: Middle atmosphere - composition and chemistry; 3334 Meteorology and Atmospheric Dynamics: Middle atmosphere dynamics (0341, 0342); 3360 Meteorology and Atmospheric Dynamics: Remote sensing; KEYWORDS: stratospheric ozone, ozone-tracer correlations, ILAS

Citation: Khosrawi, F., R. Müller, M. H. Proffitt, and H. Nakajima (2004), Monthly averaged ozone and nitrous oxide from the Improved Limb Atmospheric Spectrometer (ILAS) in the Northern and Southern Hemisphere polar regions, J. Geophys. Res., 109, D10301, doi:10.1029/2003JD004365.

\section{Introduction}

[2] Ozone $\left(\mathrm{O}_{3}\right)$ mixing ratios in the lower stratosphere are highly variable both due to the strong variability in $\mathrm{O}_{3}$ photochemistry with latitude, altitude and season, and due to the seasonality of the atmospheric transport vertically and

\footnotetext{
${ }^{1}$ Ozone Layer Research Project, National Institute for Environmental Studies, Tsukuba, Japan.

${ }^{2}$ Also at ICG-I, Forschungszentrum Jülich, Jülich, Germany,

${ }^{3}$ ICG-I, Forschungszentrum Jülich, Jülich, Germany.

${ }^{4}$ Atmospheric Research and Environment Programme/Environment Division, World Meteorological Organization, Geneva, Switzerland.

Copyright 2004 by the American Geophysical Union. 0148-0227/04/2003JD004365
}

horizontally [e.g., Dobson et al., 1973; Proffitt et al., 2003]. Variability in ozone that is due to recent transport may mask photochemical changes. Ertel's potential vorticity (PV) may be considered to be conserved in the lower stratosphere over a period of a few days to a few weeks and can therefore be used as a tracer of transport [e.g., Danielsen, 1968; McIntyre, 1992]. Therefore PV has been used to infer an "equivalent latitude" for an air parcel [Butchart and Remsberg, 1986], which constitutes an estimate of the parcel's average recent latitude [Strahan et al., 1999]. Equivalent latitude may therefore be used as a "coordinate" for the reconstruction of ozone fields from observational data sets with limited spatial coverage [e.g., Lary et al. 1995]. Proffitt et al. [2003] suggest an alternative concept by using high-resolution nitrous oxide $\left(\mathrm{N}_{2} \mathrm{O}\right)$ instead of $\mathrm{PV}$ 
or equivalent latitude, and examine the observed variations in the simultaneously measured $\mathrm{O}_{3}$ through scatterplots. The widespread use of scatterplots of long-lived trace gases was initiated by Kelly et al. [1989]. However, scatterplots of long-lived trace gases have already been used since the 1960s, as discussed in detail by Sankey and Sheperd [2003]. Scatterplots of long-lived trace gases and $\mathrm{NO}_{y}, \mathrm{HCl}$, and $\mathrm{O}_{3}$ in particular, have been used since the early nineties for the identification of physicochemical changes which are evident in measurements taken at a particular point in time [e.g., Fahey et al., 1990; Proffitt et al., 1990; Müller et al., 1996; Tilmes et al., 2003]. The method proposed by Proffitt et al. [2003], in contrast, involves seasonally averaged $\mathrm{O}_{3}$ and $\mathrm{N}_{2} \mathrm{O}$ data and thus allows ozone distributions to be characterized seasonally, a task that has historically proven to be challenging [Dütsch, 1982; London, 1985]. The method further constitutes a potential tool for testing atmospheric photochemical models and detecting future changes in stratospheric ozone [Proffitt et al., 2003].

[3] $\mathrm{O}_{3}$ variations are due to $\mathrm{O}_{3}$ photochemistry and transport through advection and mixing. $\mathrm{O}_{3}$ is produced throughout the year primarily in the tropical stratosphere with a peak production rate occurring at an altitude of $\approx 30 \mathrm{~km} . \mathrm{O}_{3}$ chemistry outside the tropics predominantly results in a net $\mathrm{O}_{3}$ loss that is particularly pronounced at polar latitudes during early summer and late winter in the Arctic and Antarctic with maximal $\mathrm{O}_{3}$ loss occurring during southern hemispheric spring over the Antarctic. Through the Brewer-Dobson circulation tropical, $\mathrm{O}_{3}$-rich air is transported toward the poles. The tropical $\mathrm{O}_{3}$ rich air thus reaches mid and high latitudes with seasonally dependent intensity.

[4] $\mathrm{N}_{2} \mathrm{O}$ is photochemically long-lived in the lower stratosphere with a local lifetime of many years. Its sources are exclusively in the troposphere and it has a photochemical sink in the middle and upper stratosphere, so that, throughout the lower stratosphere, the mean $\mathrm{N}_{2} \mathrm{O}$ mixing ratio decreases with increasing altitude. Measurements of $\mathrm{N}_{2} \mathrm{O}$ [Strahan et al., 1999] have shown that the zonally averaged lower stratospheric $\mathrm{N}_{2} \mathrm{O}$ mixing ratios vary systematically with season, latitude and altitude. They also demonstrated that local changes from the seasonal zonal mean profiles can be interpreted as the result of recent stratospheric transport.

[5] Here, we apply the methodology proposed by Proffitt et al. [2003] to separate ozone changes due to photochemical and transport processes. We use $\mathrm{N}_{2} \mathrm{O}$ and $\mathrm{O}_{3}$ measured by the Improved Limb Atmospheric Spectrometer (ILAS), which was launched on board the Advanced Earth Observing Satellite (ADEOS) on 17 August 1996 [Sasano et al., 1999; Nakajima et al., 2002]. In contrast to the study of Proffitt et al. [2003], who considered data of the Northern Hemisphere for 8 years, the coverage of ILAS allows only a study of the high latitude region and the measuring period is limited to 8 months. However, the advantages of the ILAS data set for such a study, compared to the ER-2 data used by Proffitt et al. [2003], are an extended altitude and potential temperature range, and the availability of Southern Hemisphere data. While the ER-2 measurements are limited to altitude levels below $20 \mathrm{~km}$ or potential temperature levels below $520 \mathrm{~K}$, ILAS measurements are available up to an altitude level of $70 \mathrm{~km}$ corresponding to a potential temperature level of $3500 \mathrm{~K}$. Thus the usage of the ILAS data allows the study of Proffitt et al. [2003] to be extended from the lower stratosphere into the middle and upper stratosphere. Further, such an analysis is presented here for the first time for the Southern Hemisphere. During the ILAS measuring period, a complete Arctic winter was observed and in the Southern Hemisphere the time of the breakup of the southern hemispheric vortex is covered by the measurements. Moreover, owing to the good temporal coverage of the high-latitude region by ILAS (about 14 profiles per day) we can produce monthly scatterplots instead of seasonal scatterplots as in the work of Proffitt et al. [2003]. This allows us to investigate monthly ozone changes. In this way, a more detailed analysis of the temporal development of the ozone changes can be given.

[6] Several studies have been previously performed investigating ozone changes during the Arctic winter 1997 using ILAS observations [e.g., Sasano et al., 2000; McKenna et al., 2002; Tilmes et al., 2003; Terao et al., 2002]. The breakup of the southern hemispheric vortex was investigated by Choi et al. [2002] using ILAS methane measurements. The Arctic polar region in 1997 was also observed by HALOE and investigations of summer and winter ozone losses were presented by, e.g., Pierce et al. [1997, 1999], Fairlie et al. [1999], and Müller et al. [1997b]. Especially, the strong descent in the center of the polar vortex and the fact that low ozone mixing ratios occur due to dynamical and photochemical processes was reported in studies based on HALOE observations [Russell et al., 1993; Pierce et al., 1999].

\section{ILAS Data and Analysis}

[7] The ILAS instrument was developed by the Environment Agency of Japan and it was operated on board the Advanced Earth Observing Satellite (ADEOS) of the National Space Development Agency (NASDA). ILAS uses the solar occultation technique and operated continuously during an 8-month period from 30 October 1996 to 30 June 1997 [Sasano et al., 1999]. Measurements were made about fourteen times per day in the high-latitude region of both hemispheres. The latitudes from $58^{\circ} \mathrm{N}$ to $73^{\circ} \mathrm{N}$ and from $65^{\circ} \mathrm{S}$ to $90^{\circ} \mathrm{S}$ were covered during the measuring period (see electronic supplement ${ }^{1}$ ). We use Version 6.0 of the ILAS data. The data-processing algorithm for the former Version 5.20 is described in detail in the work of Yokota et al. [2002]. Eight gases were originally measured by ILAS: $\mathrm{O}_{3}$, $\mathrm{HNO}_{3}, \mathrm{NO}_{2}, \mathrm{~N}_{2} \mathrm{O}, \mathrm{CH}_{4}, \mathrm{H}_{2} \mathrm{O}, \mathrm{CFC}-11$, and CFC-12. Recently, $\mathrm{ClONO}_{2}$ and $\mathrm{N}_{2} \mathrm{O}_{5}$ have been added to the ILAS retrieval algorithm as trace compounds (Nakajima et al., to be submitted). Here we focus on the measurements of nitrous oxide $\left(\mathrm{N}_{2} \mathrm{O}\right)$ and ozone $\left(\mathrm{O}_{3}\right)$. Validation of ILAS Version 5.20 data shows a good agreement of $\mathrm{O}_{3}$ with its correlative data between 11 and $64 \mathrm{~km}$ [Sugita et al., 2002] and between 10 and $40 \mathrm{~km}$ for $\mathrm{N}_{2} \mathrm{O}$ [Kanzawa et al., 2002]. The recent Version 6 data are improved compared to the former Version 5.20 data owing to a revised determination of the tangent height, a revised calculation of absorption

\footnotetext{
${ }^{1}$ Auxiliary materials are available at ftp://ftp.agu.org/apend/jd/ 2003JD004365.
} 
coefficients, updated molecular spectroscopic parameters and revised initial values of climatological parameters like gas concentration, temperature and pressure. Vertical profiles of $\mathrm{O}_{3}$ and $\mathrm{N}_{2} \mathrm{O}$ were measured in the range of $10 \mathrm{~km}$ or cloud top up to $70 \mathrm{~km}$. The high spatial and temporal coverage of ILAS observations inside the polar vortex makes this data set particularly suitable for studies of Arctic and Antarctic ozone loss. For example, Tilmes et al. [2003] calculated Arctic ozone loss using ILAS data and compared their results to observations by the Halogen Occultation Experiment (HALOE). Arctic ozone loss rates were deduced by Terao et al. [2002] employing the Match method with ILAS measurements.

[8] Here, we calculate monthly averages of tracer-tracer correlations of $\mathrm{O}_{3}$ versus $\mathrm{N}_{2} \mathrm{O}$. The ILAS data were organized monthly for both hemispheres by partitioning the data into equal bins of altitude or potential temperature. Within these bins of altitude or potential temperature the $\mathrm{O}_{3}$ and $\mathrm{N}_{2} \mathrm{O}$ data is block averaged over a fixed interval of $\mathrm{N}_{2} \mathrm{O}$ (20 ppbv). The averaging of data was performed twice, once for the altitude and potential temperature range covered by ILAS (10 to $50 \mathrm{~km}$ and 350 to $1000 \mathrm{~K}$ ) and once for the altitude and potential temperature range covered by the ER-2 aircraft (12 to $20 \mathrm{~km}$ and 360 to $520 \mathrm{~K})$. The latter analysis was performed to compare our results deduced from ILAS data with the Northern Hemisphere study of Proffitt et al. [2003], who used an extensive high altitude aircraft (ER-2) data set and a limited balloon data set for greater altitudes. Additionally, a comparison is made for a separation of the ILAS data into inside and outside vortex air. For this purpose we used the PV values characterizing the polar vortex edge for the ILAS measuring period on 23 potential temperature surfaces, calculated by G. Bodeker using the algorithm of Nash et al. [1996], and meteorological fields from the UK Met Office (UKMO). We use the PV value at the vortex edge on the $475 \mathrm{~K}$ potential temperature level and calculate the vortex edge for the potential temperature level of each ILAS measurement point using a scaling based on a generalized form of modified PV [Lait, 1994; Müller and Günther, 2003]. The PV at the vortex edge determined in this way is in good agreement with the values calculated using the Nash et al. [1996] algorithm. All averaged data points of the tracer correlations of $\mathrm{N}_{2} \mathrm{O}$ versus $\mathrm{O}_{3}$ and the corresponding standard deviations derived here are available as an electronic supplement to the paper.

\section{3. $\mathrm{N}_{2} \mathrm{O} / \mathrm{O}_{3}$ Distribution by Altitude}

[9] Figures 1 and 2 show the resulting families of $\mathrm{N}_{2} \mathrm{O} / \mathrm{O}_{3}$ curves after binning by altitude (10 to $50 \mathrm{~km}$ with $\Delta \mathrm{h}=$ $5 \mathrm{~km}$ ) for the Northern and Southern Hemisphere, respectively. In both hemispheres the families of curves are separated and generally do not cross. During the fall and winter months, in both hemispheres, a negative correlation of $\mathrm{N}_{2} \mathrm{O}$ and $\mathrm{O}_{3}$ is found for altitudes below $25 \mathrm{~km}$ while the curves at the levels above are positively correlated. The positive correlation at greater altitudes is caused by the descent of air from above the $\mathrm{O}_{3}$ maximum that brings down air characterized by lower $\mathrm{O}_{3}$ and $\mathrm{N}_{2} \mathrm{O}$ mixing ratios [e.g., Proffitt et al., 2003]. Thus descent causes a steepening of the curves. The stronger the descent the stronger the steepening. A particularly strong descent in the Antarctic vortex core in spring was observed in the HALOE $\mathrm{CH}_{4}$ measurements in 1991 by Russell et al. [1993]. Very strong descent is likewise observed in the HALOE measurements in the Northern Hemisphere polar region in March and April albeit with somewhat greater $\mathrm{CH}_{4}$ mixing ratios in the polar vortex [Müller et al., 1996, 1999]. The slope of the curves is further influenced by photochemical $\mathrm{O}_{3}$ destruction [Proffitt et al., 2003]. Photochemical ozone destruction in the lower stratosphere in summer [Johnston, 1975; Farman, 1985; Pierce et al., 1999; Brühl and Crutzen, 2000; Crutzen and Brühl, 2001] tends to reduce ozone mixing ratios and thus the magnitude of the negative $\mathrm{O}_{3} / \mathrm{N}_{2} \mathrm{O}$ slope. In summer (e.g., in June in the Northern Hemisphere) when at highlatitudes ozone loss is strong and descent is weak a negative correlation can be found at all altitudes.

\subsection{Northern Hemisphere}

[10] During November and December (Figures 1a and 1b) the families of curves are negatively correlated for altitudes below $25 \mathrm{~km}$ and positively correlated for altitudes above. In the northern hemispheric winter 1996/1997 the vortex formed in November, but was strongly disturbed at the end of November. However, after reforming in late December the vortex lasted unusually long until late in April. Unusually warm temperatures were found in the lower stratosphere until early January. However, record low temperatures were reached in March and April 1997 [Coy et al., 1997]. From January on, a gradual change in correlation of the $20 \pm 2.5 \mathrm{~km}$ curve with an inflection at $150 \mathrm{ppbv}$ (January) and 190 ppbv (May) of $\mathrm{N}_{2} \mathrm{O}$ can be seen. A similar gradual change is seen in the $25 \pm 2.5 \mathrm{~km}$ curve with an inflection in May (Figure 1g) at 110 ppbv. This change in correlation can be attributed to photochemical ozone destruction in the polar vortex [Proffitt et al., 2003]. Furthermore, the curves for altitudes above $20 \mathrm{~km}$ (January to May) show a decreasing slope which may be attributed to a decrease in diabatic descent. In June, after the breakup of the polar vortex at all altitudes, the correlation is generally negative (Figure 1h). Further, the complete mixing of vortex remnant air with outside vortex air dilutes the low $\mathrm{O}_{3}$ and $\mathrm{N}_{2} \mathrm{O}$ mixing ratios which were previously present at altitudes between 15 and $25 \mathrm{~km}$.

\subsection{Southern Hemisphere}

[11] For altitudes above $20 \mathrm{~km}$ the families of curves are, in general, positively correlated except for February and March (Figures $2 \mathrm{~d}$ and $2 \mathrm{e}$ ) where a negative correlation is found at all altitudes. In November and December (Figures $2 \mathrm{a}$ and $2 \mathrm{~b}$ ) preserved ozone loss is evident for the $20 \pm 2.5 \mathrm{~km}$ and $25 \pm$ $2.5 \mathrm{~km}$ curves. In $20 \pm 2.5 \mathrm{~km}$ the inflection is found at 150 ppbv $\mathrm{N}_{2} \mathrm{O}$ in November with a minimum in $\mathrm{O}_{3}$ of 1 ppmv $\mathrm{O}_{3}$ at 70 to 110 ppbv $\mathrm{N}_{2} \mathrm{O}$ and an inflection at 190 ppbv $\mathrm{N}_{2} \mathrm{O}$ in December with a minimum in $\mathrm{O}_{3}$ of 1.5 ppmv at 70 to 90 ppbv $\mathrm{N}_{2} \mathrm{O}$. With the breakup of the vortex in December [Choi et al., 2002], the ozone distribution recovers toward February then showing a negative correlation at all altitudes. Summer ozone loss [Johnston, 1975; Farman, 1985] is evident from January to March noticeable by a general decline of ozone at altitude levels above $20 \mathrm{~km}$. From April on, the ozone distribution changes to positively correlated for altitudes above $20 \mathrm{~km}$ and negatively correlated for altitudes 

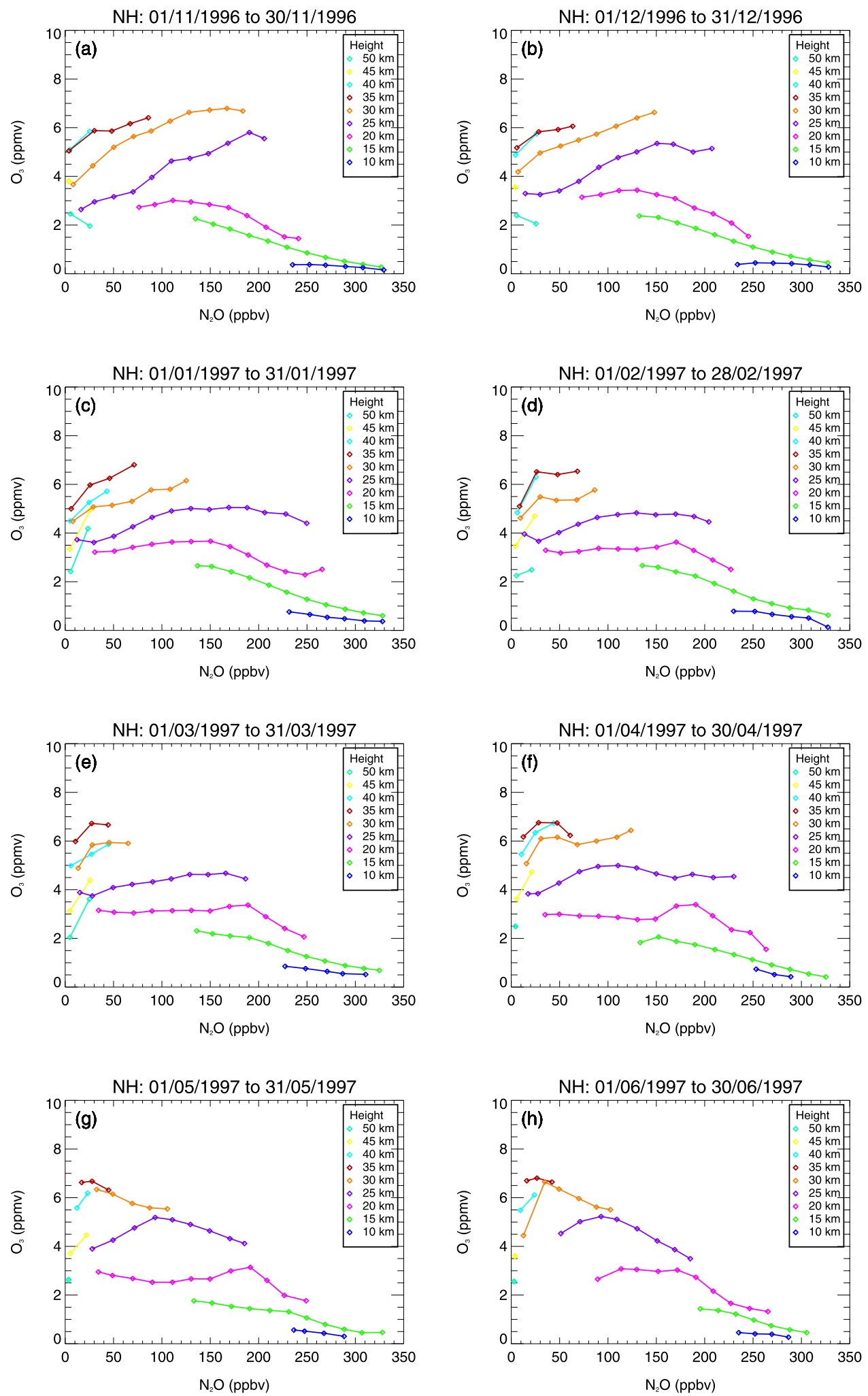

Figure 1. Northern hemispheric monthly averaged $\mathrm{N}_{2} \mathrm{O}$ and $\mathrm{O}_{3}$ measured by ILAS and binned by altitude. (a-h) November 1996 to June 1997.

below due to descent of air from above the $\mathrm{O}_{3}$ maximum. The steepest slope of the curves is found in April indicating that the strongest descent in the southern hemispheric fall has recently occurred (Figure 2f).

\section{4. $\mathrm{N}_{2} \mathrm{O} / \mathrm{O}_{3}$ Distribution by Potential Temperature}

[12] Figures 3 and 4 show the resulting families of curves after binning by potential temperature $(350 \mathrm{~K}$ to $1000 \mathrm{~K}$ 

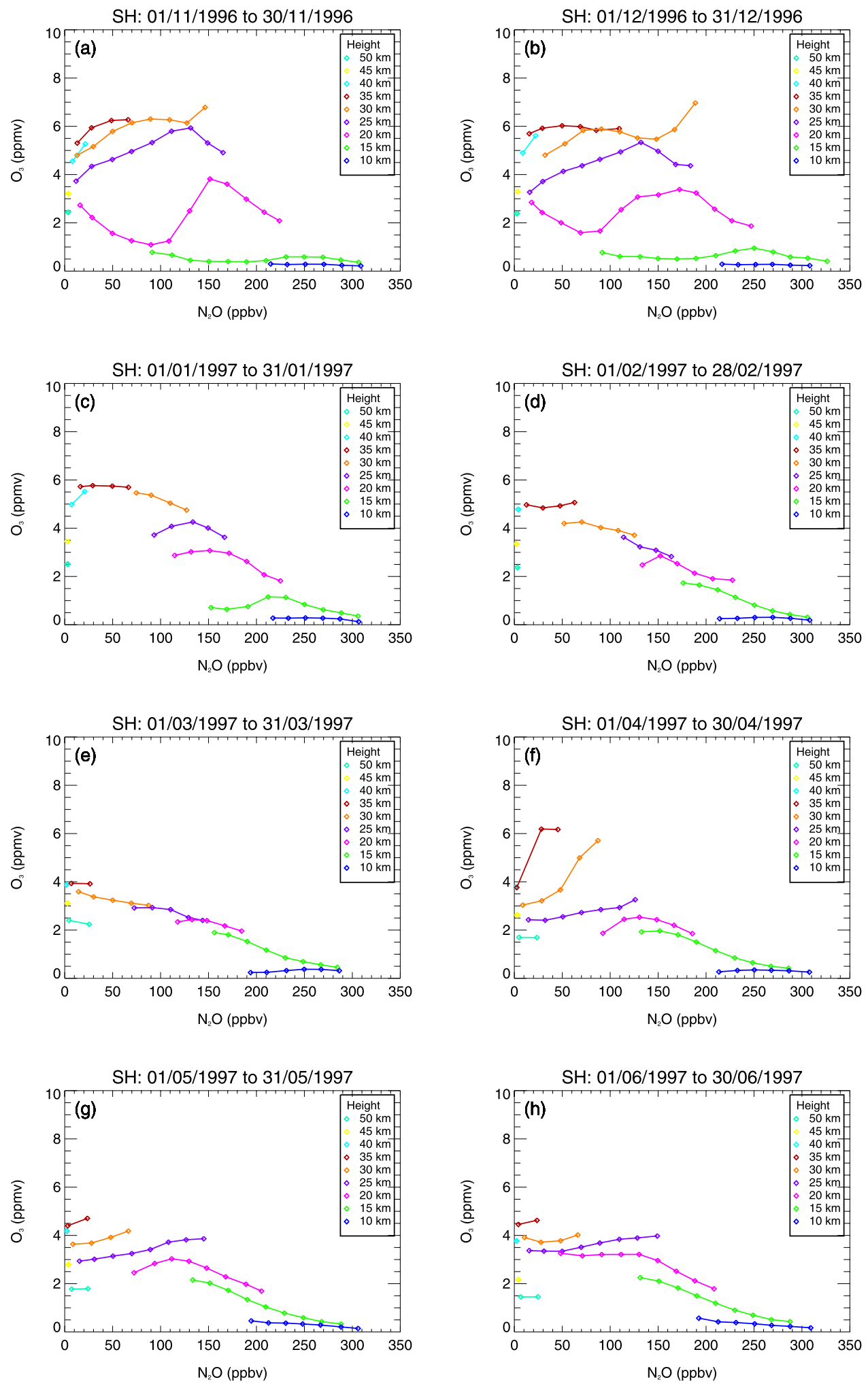

Figure 2. Southern hemispheric monthly averaged $\mathrm{N}_{2} \mathrm{O}$ and $\mathrm{O}_{3}$ measured by ILAS and binned by altitude. $(\mathrm{a}-\mathrm{h})$ November 1996 to June 1997.

with $\Delta \Theta=50 \mathrm{~K})$ for the Northern and Southern Hemisphere, respectively. In both hemispheres the families of curves are separated and generally do not cross. Further, the curves are much more evenly spaced than for the altitude binning. This is due to the fact that transport occurs mainly on isentropic levels. The good separation makes these curves particularly suitable for comparison with the results from model calculations. While the families of curves are flat or negatively correlated at lower potential temperatures, they are positively correlated at the levels above. An 

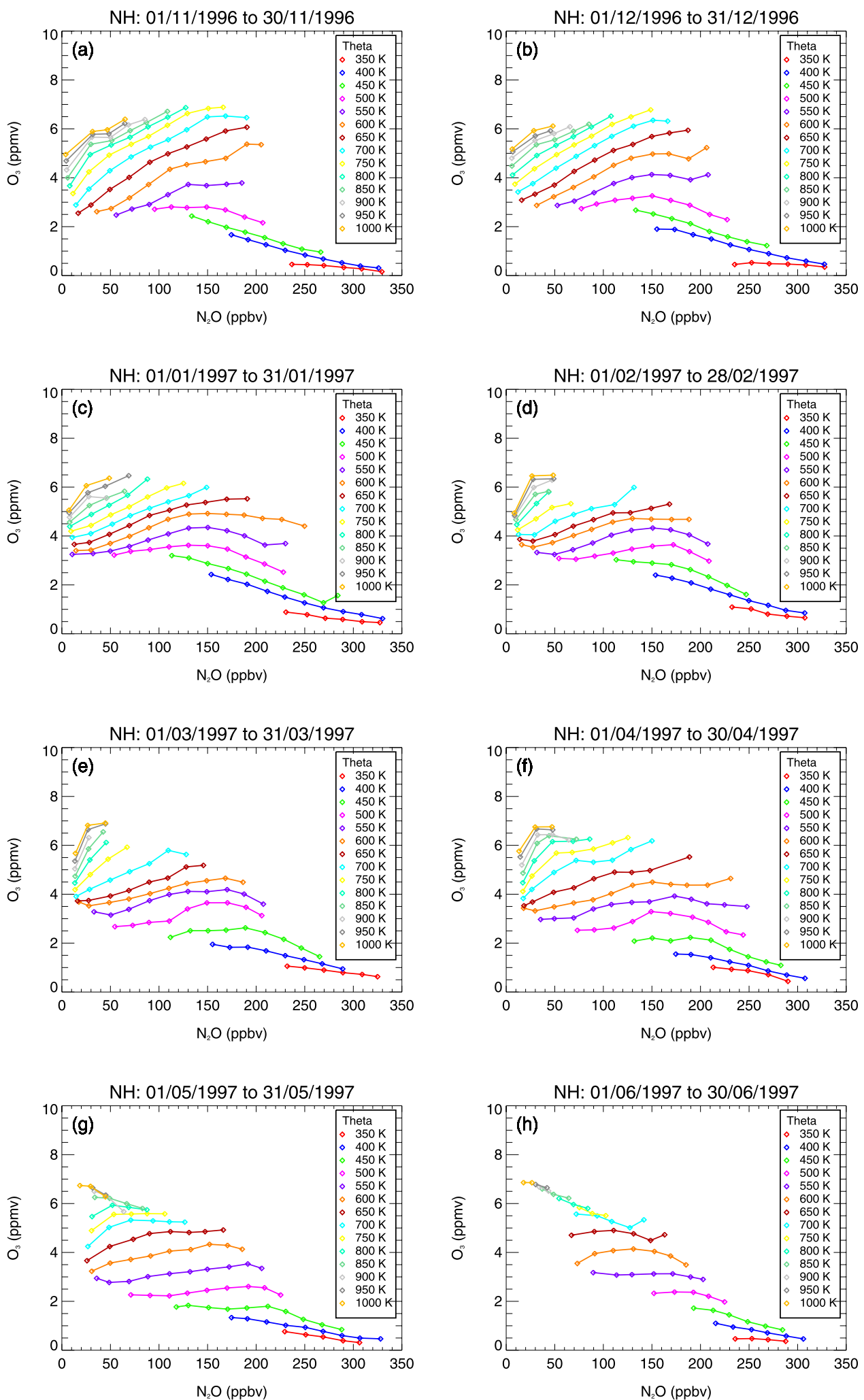

Figure 3. Northern hemispheric monthly averaged $\mathrm{N}_{2} \mathrm{O}$ and $\mathrm{O}_{3}$ measured by ILAS and binned by potential temperature. $(\mathrm{a}-\mathrm{h})$ November 1996 to June 1997.

exception is June in the Northern Hemisphere and March in the Southern Hemisphere where a negative correlation is found at all but the lowest level. Within each monthly family of curves an increase of $\mathrm{O}_{3}$ with potential tempera- ture $(\Theta)$ can be found for a constant value of $\mathrm{N}_{2} \mathrm{O}$. This dependence was observed previously by Proffitt et al. $[1990,1993,2003]$ and was termed " $\mathrm{O}_{3}-\Theta$ dependence". Because within the Arctic vortex the $\mathrm{O}_{3}-\Theta$ dependence 

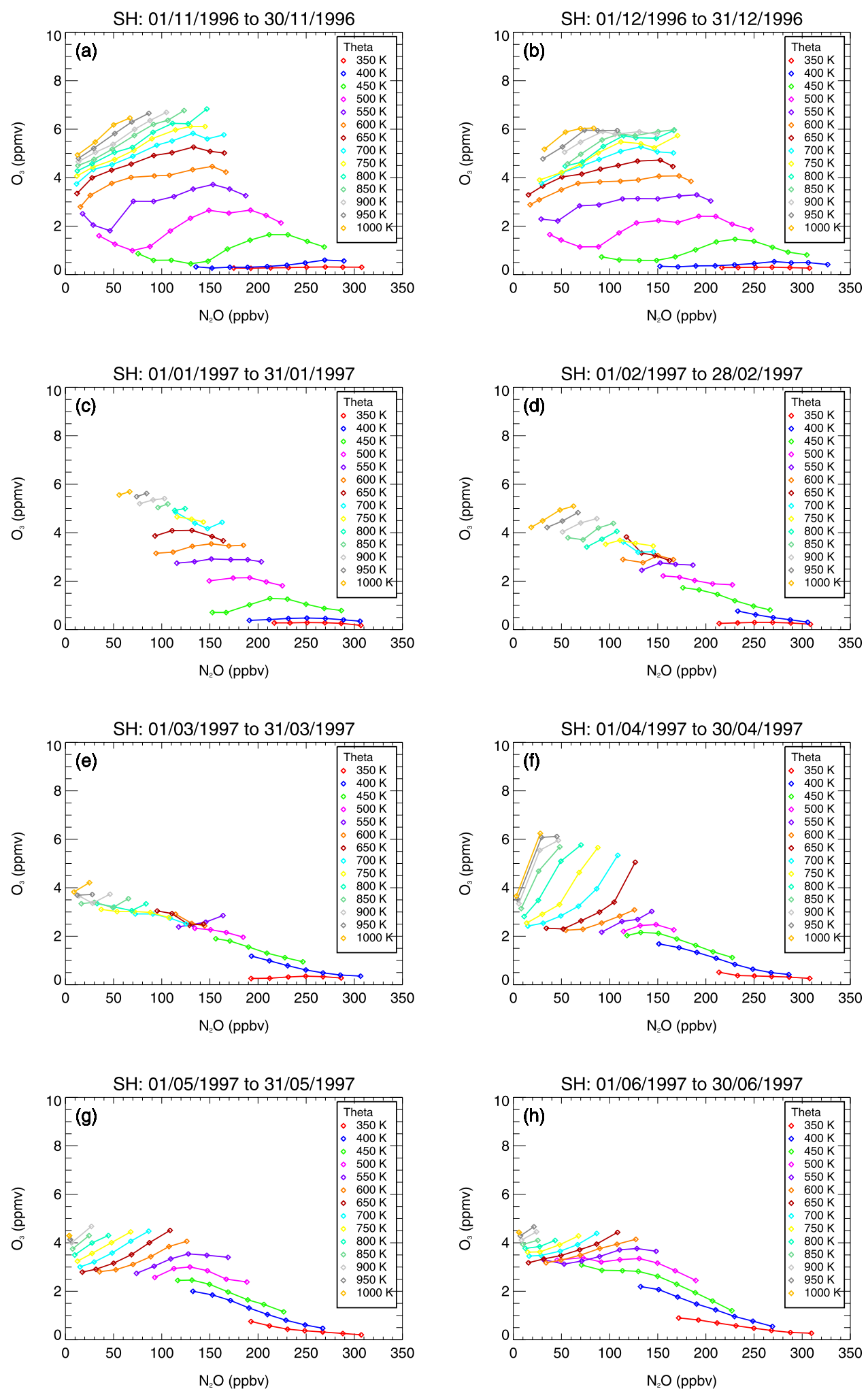

Figure 4. Southern hemispheric monthly averaged $\mathrm{N}_{2} \mathrm{O}$ and $\mathrm{O}_{3}$ measured by ILAS and binned by potential temperature. (a-h) November 1996 to June 1997.

cannot be entirely explained by descent from above the $\mathrm{O}_{3}$ maximum they concluded that this finding also requires photochemical winter loss of $\mathrm{O}_{3}$ in the presence of diabatic cooling. Further, since the flow and the chemistry proceed at the same time the vortex can be viewed as a "flowing processor" of $\mathrm{O}_{3}$ as described in the work of Tuck and Proffitt [1997] and Proffitt et al. [2003]. Proffitt et al. [2003] also argue that the positive slope of $\mathrm{O}_{3}$ versus $\mathrm{N}_{2} \mathrm{O}$ isentropes at the higher potential temperature levels (generally above $500 \mathrm{~K}$ ) and its gradual change in slope to negative 

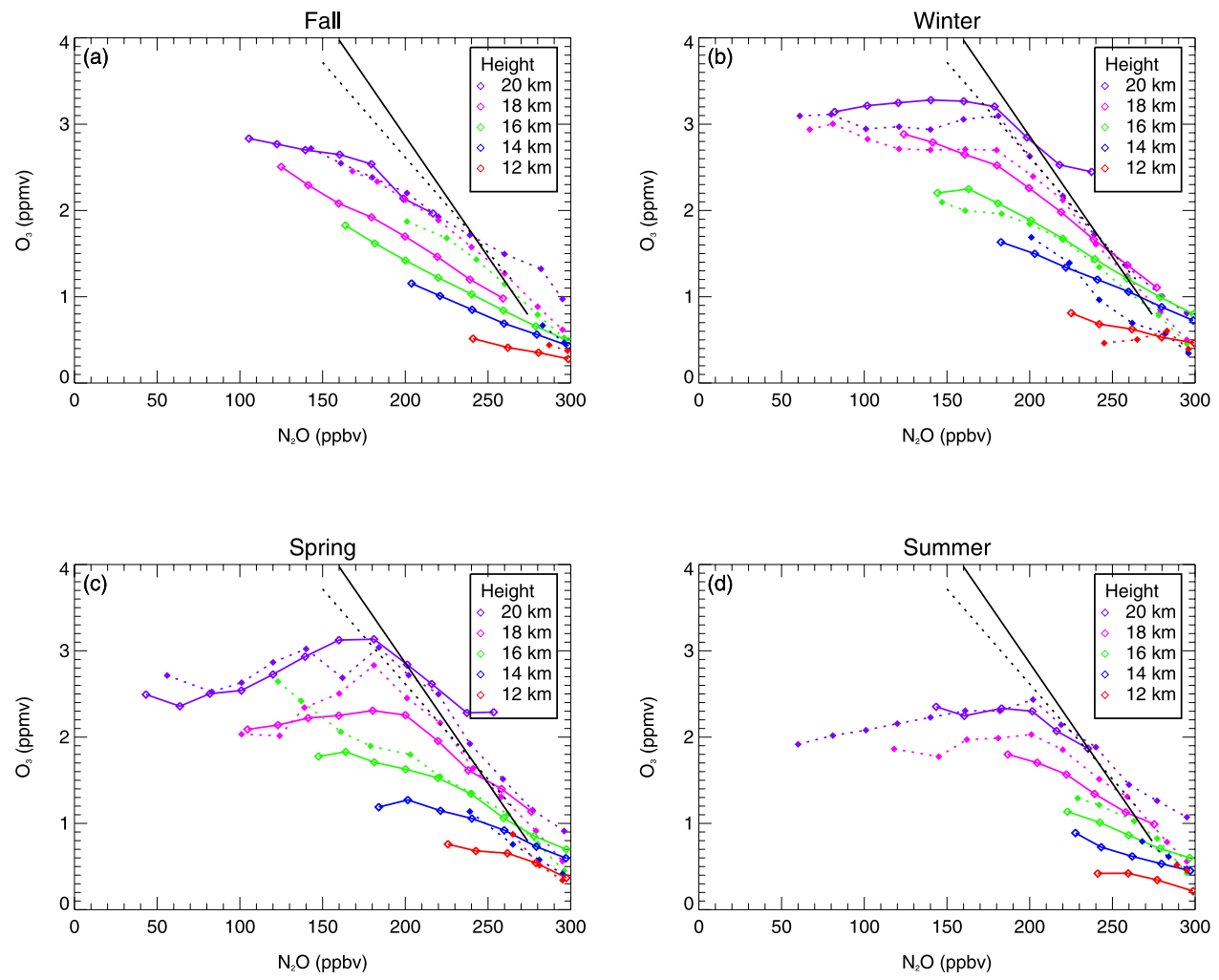

Figure 5. Seasonal averaged $\mathrm{N}_{2} \mathrm{O}$ and $\mathrm{O}_{3}$. Comparison of ER-2 data of Proffitt et al. [2003] (dashed lines) with ILAS data (solid lines) binned by altitude for the Northern Hemisphere. Additionally the midlatitude (dotted line) and vortex exterior (solid line) references from 1989 AASE ER-2 data are shown [Proffitt et al., 2003].

can be explained by descent from above the $\mathrm{O}_{3}$ maximum. The level where this slope reversal occurs is dependent on season and is influenced by photochemical $\mathrm{O}_{3}$ production and $\mathrm{O}_{3}$ loss processes [Proffitt et al., 2003]. However, as stated by Proffitt et al. [2003] this rather simplistic picture may not represent all factors affecting these families of curves, nevertheless, it is a useful approximation.

\subsection{Northern Hemisphere}

[13] The families of curves change from negatively correlated at the lower potential temperature levels to positively correlated at the upper levels due to descent from above the $\mathrm{O}_{3}$ maximum. Because descent is most intense in fall and winter this behavior is particularly pronounced between November and February (Figures $3 a-3 d$ ) whereby the steepest slope of curves is found for November and December. The level where this slope reversal occurs is dependent upon season and is influenced by photochemical processes [Proffitt et al., 2003]. Beginning in January, the slope starts to change gradually from positive to negative along particular isentropes. Photochemical $\mathrm{O}_{3}$ destruction is evident from January to March in 450 to $500 \mathrm{~K}$ at low $\mathrm{N}_{2} \mathrm{O}$ values. Previous studies reported evidence for chlorinecatalyzed photochemical ozone destruction in the lower stratosphere during this period based on model results [McKenna et al., 2002] and based on satellite observations [Pierce et al., 1997; Terao et al., 2002; Tilmes et al., 2003]. Toward May (Figure 3d) where descent is weak the families of curves begin to flatten. Some remnants of polar vortex air can be found at $\mathrm{N}_{2} \mathrm{O}$ values of 30 to 70 ppbv. Summer $\mathrm{O}_{3}$ loss due to $\mathrm{NO}_{x}$-catalyzed $\mathrm{O}_{3}$ loss cycles, which is expected to occur with increasing intensity from May on [Crutzen and Brühl, 2001], will reduce $\mathrm{O}_{3}$ mixing ratios. The ozone mixing ratios on given potential temperature levels below about $500 \mathrm{~K}$ are lower in June than in April (Figures $3 \mathrm{f}-3 \mathrm{~h}$ ). In June (Figure $3 \mathrm{~h}$ ) the curves are flat to slightly negatively correlated.

\subsection{Southern Hemisphere}

[14] The families of curves in the Southern Hemisphere are less evenly separated than in the Northern Hemisphere. In November and December (Figures $4 a$ and $4 b$ ) none of the curves show a negative correlation. In November and December preserved winter ozone loss is found at levels between 450 and $550 \mathrm{~K}$ at $\mathrm{N}_{2} \mathrm{O}$ values around 50 to $100 \mathrm{ppbv}$ as a minimum in the $\mathrm{O}_{3}$ mixing ratio. These remnants of vortex air disappeared by January because of mixing. This effect is noticeable as a disappearance of the low $\mathrm{N}_{2} \mathrm{O}$ mixing ratios on given potential temperature levels between December and January that are characteristic of descended vortex air (Figures $4 \mathrm{~b}$ and $4 \mathrm{c}$ ). The development of the $\mathrm{O}_{3} / \mathrm{N}_{2} \mathrm{O}$ relation in austral summer from January to March is driven by the summertime polar ozone loss [Johnston, 1975; Farman, 1985] noticeable as the decline of ozone above $\approx 550 \mathrm{~K}$ during this period. With the begin of the polar vortex formation in April (Figure 4f) and the associated diabatic descent of air masses in the polar vortex region the curves presume a steep slope with a positive 

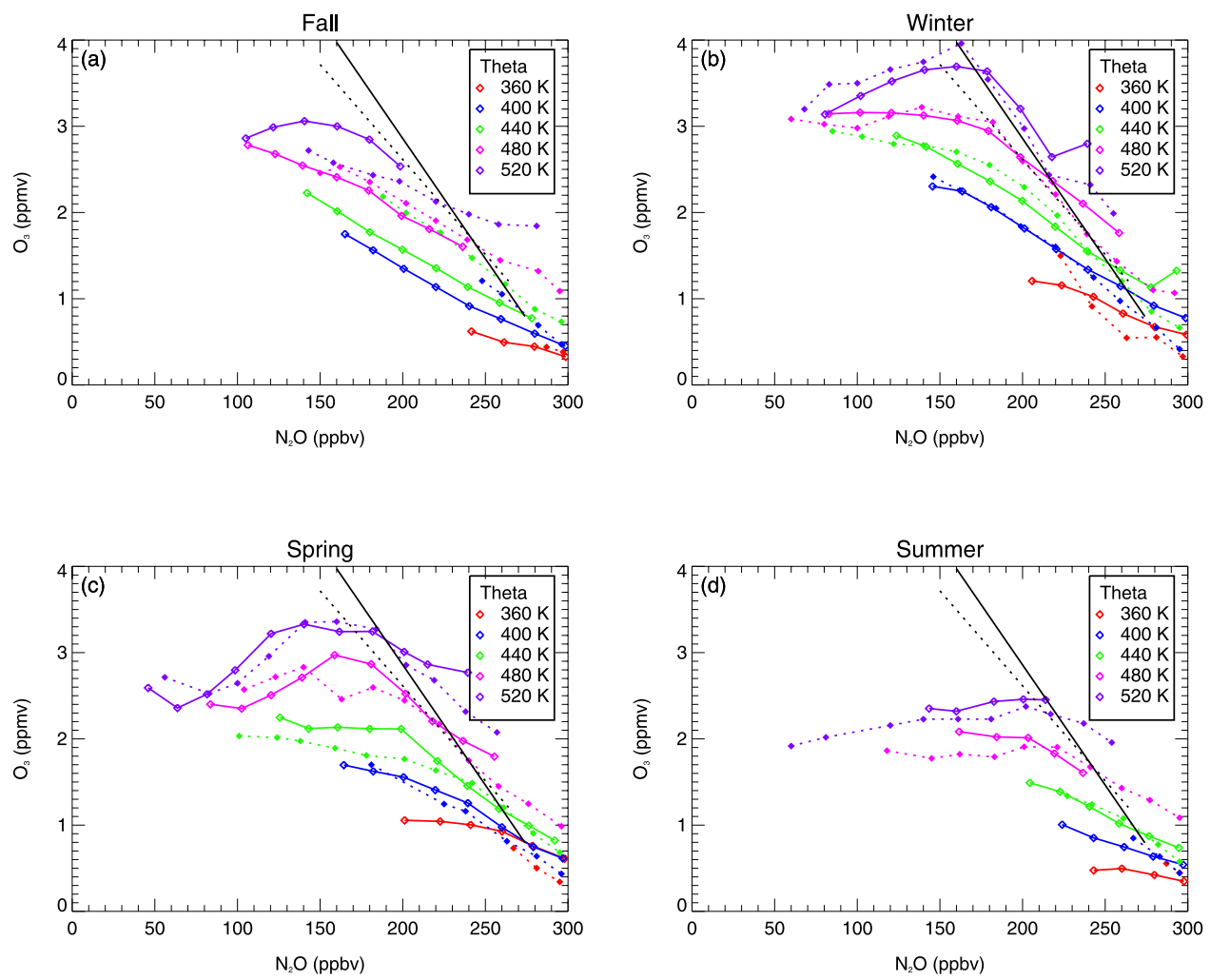

Figure 6. Seasonal averaged $\mathrm{N}_{2} \mathrm{O}$ and $\mathrm{O}_{3}$. Comparison of ER-2 data of Proffitt et al. [2003] (dashed lines) with ILAS data (solid lines) binned by potential temperature for the Northern Hemisphere. ILAS data from above the ER-2 flight level of $\approx 20 \mathrm{~km}$ were excluded. Additionally, the midlatitude (dotted line) and vortex exterior (solid line) references from 1989 AASE ER-2 data are shown [Proffitt et al., 2003].

correlation in the upper levels and a negative correlation in the lower levels. The negative correlations in the lower levels appear because these levels are not influenced by the descent of air from the upper levels. In May and June (Figures $4 \mathrm{~g}$ and $4 \mathrm{~h}$ ) the slope of the positively correlated curves is not as steep as in April, but the proportion between positively and negatively correlated curves is the same. Likewise, the potential temperature level of the slope reversal $(\approx 500 \mathrm{~K})$ is similar from April to June.

\section{Comparison With ER-2 Measurements}

[15] In the following, the ILAS data are compared with the study of Proffitt et al. [2003], who performed a similar analysis using seasonally averaged ER-2 data (Figures 5 and 6). For this comparison, the ILAS data are seasonally organized into potential temperature and altitude bins in exactly the same way as was done for the ER-2 data by Proffitt et al. [2003]. The seasons are considered in the usual meteorological sense beginning with December, January and February as winter. However, in the figures we start with fall because the ILAS measurements started in November. The comparison for fall and summer is of limited value due to the lack of ILAS data. For these seasons only one month of ILAS data is available. Therefore for both the altitude and potential temperature bins a good agreement can be only expected for the spring and winter comparison. For the comparison of the data binned by potential temperature ILAS data from above the ER-2 flight level of $\approx 20 \mathrm{~km}$ were excluded. As in the study of Proffitt et al. [2003], the 1989 AASE (Airborne Arctic Stratospheric Expedition) midlatitude and vortex exterior reference curves are included in the figures to help identify the air of tropical and air of polar character.

[16] Comparing the results derived from ER-2 and ILAS data one should bear in mind that there are significant differences between the two data sets. While Proffitt et al. [2003] use ER-2 data from 8 years (1989-1997), ILAS measured only 8 months in 1996-1997. Thus in the ILAS data the characteristics of the winter 1996-1997 will be strongly present. Additionally, the ER-2 data cover the whole Northern Hemisphere while ILAS covers only the polar latitudes. Therefore a binning of ILAS data according to latitude, as done for the ER-2 data by Proffitt et al. [2003], is not possible. Concerning the altitude bins differences can occur due to the different altitude determination. While ILAS uses a geometric altitude the ER-2 aircraft uses a pressure altitude. Differences between pressure altitude and geometric altitude are in general small below $20 \mathrm{~km}$. However, differences of up to $2 \mathrm{~km}$ can occur.

\section{1. $\mathrm{N}_{2} \mathrm{O} / \mathrm{O}_{3}$ Distribution by Altitude}

[17] The families of curves deduced from ER-2 and ILAS data are separated and generally do not cross. A good agreement between the curves deduced from the ILAS and the ER-2 data can be found at practically all altitudes 

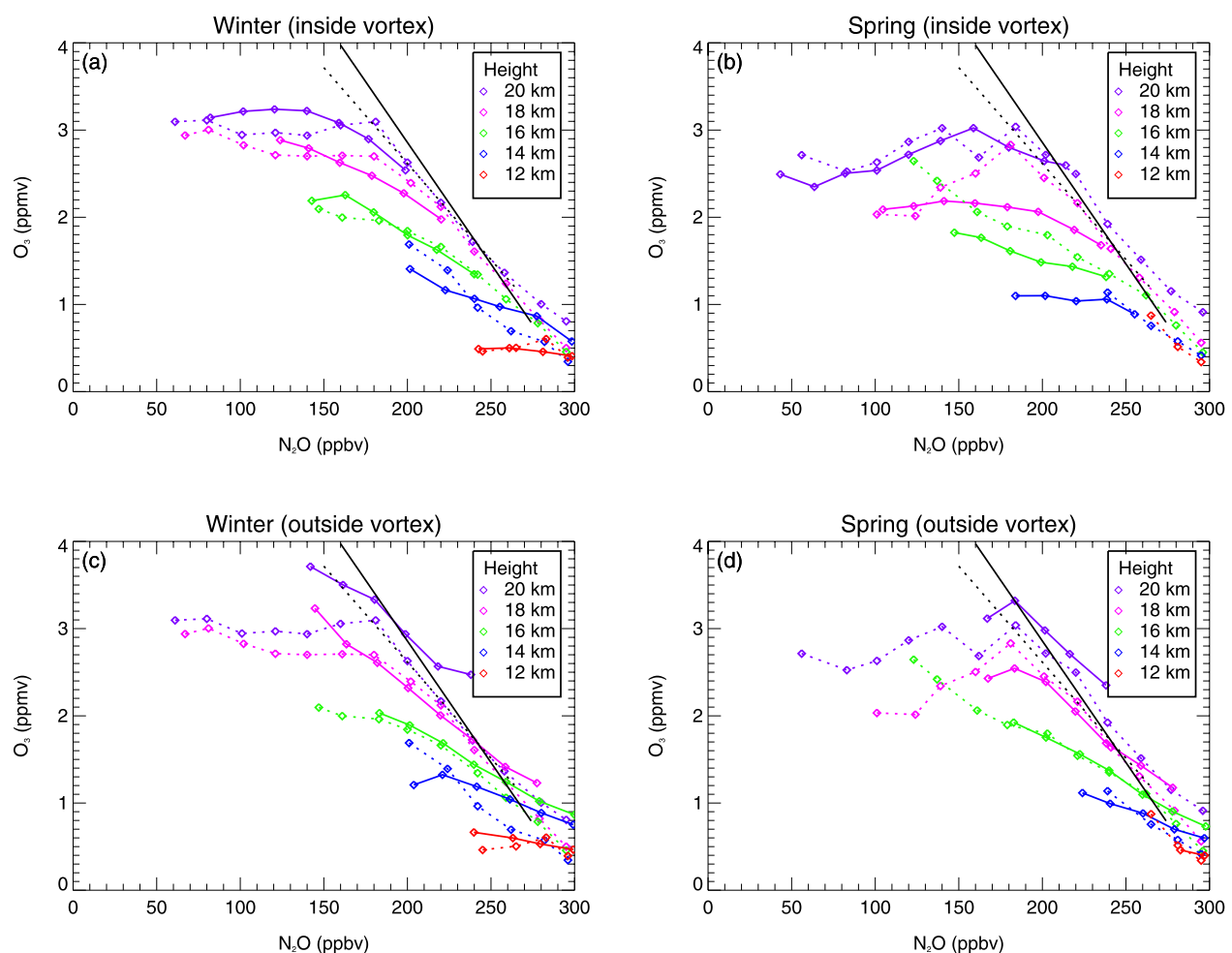

Figure 7. Seasonal averaged $\mathrm{N}_{2} \mathrm{O}$ and $\mathrm{O}_{3}$ binned by altitude for winter and spring. Comparison of ER-2 data of Proffitt et al. [2003] (dashed lines) with ILAS data (solid lines) for the Northern Hemisphere. The ILAS data are separated into inside and outside vortex air. Additionally the midlatitude (dotted line) and vortex exterior (solid line) references from 1989 AASE ER-2 data are shown [Proffitt et al., 2003].

in winter and spring (Figures $5 \mathrm{~b}$ and $5 \mathrm{c}$ ). The ILAS data points agree with the corresponding data points of the ER-2 analysis within the combined uncertainty deduced from the standard deviation of the averages (see electronic supplement). For fall and summer (Figures $5 \mathrm{a}$ and $5 \mathrm{~d}$ ) the data sets are not fully comparable and indeed a good agreement is found only at $20 \pm 1 \mathrm{~km}$. However, while in the ER-2 data in spring the negatively correlated $16 \pm 1 \mathrm{~km}$ curve intersects with the $18 \pm 1 \mathrm{~km}$ curve this is not found in the ILAS data and may reflect an undersampling with ER-2 data. In fall and summer, a linear relation is found at all altitudes. At $18 \pm 1 \mathrm{~km}$ and $20 \pm 1 \mathrm{~km}$ in winter and summer, photochemical $\mathrm{O}_{3}$ loss is evident from a changing slope of the curves. Data of tropical character can be found in the ER-2 data in every season at $20 \mathrm{~km}\left(\mathrm{~N}_{2} \mathrm{O} \geq 260 \mathrm{ppbv}\right)$, and is found in the ILAS high-latitude data particularly in winter but also in spring and summer.

\section{2. $\mathrm{N}_{2} \mathrm{O} / \mathrm{O}_{3}$ Distribution by Potential Temperature}

[18] As with the comparison of the altitude bins, the curves deduced from the ER-2 and ILAS data sets are separated and generally do not cross. A good agreement between the curves deduced from ILAS and the ER-2 can be found at all levels in spring and winter (Figures $6 \mathrm{~b}$ and $6 \mathrm{c})$. The ILAS data points agree with the corresponding data points of the ER-2 analysis within the combined uncertainty deduced from the standard deviation of the averages (see electronic supplement). Greater differences are found in fall and summer (Figures 6a and 6d) due to the lack of data (only one month of ILAS data compared to three months of ER-2 data). In spring and winter slightly greater ILAS ozone values are found at most levels. In fact, the ILAS ozone validation study [Sugita et al., 2002] has revealed that the ILAS ozone measurements are about $15 \%$ greater at altitudes below $20 \mathrm{~km}$ than the measurements of UV photometers such as the one employed on the ER-2.

[19] As argued by Proffitt et al. [2003], curves below $550 \mathrm{~K}$ are not greatly affected by descent from above the $\mathrm{O}_{3}$ maximum. Therefore the change in slope of the $480 \pm 20 \mathrm{~K}$ curve and the $520 \pm 20 \mathrm{~K}$ curve in winter and spring is consistent with photochemical loss of $\mathrm{O}_{3}$. While the separation in the ER-2 data is, compared to the altitude bins, much better for the potential temperature bins, in the ILAS data no difference can be found. This is likely due to the fact that the theta and altitudes isopleths diverge much less when restricted to high latitudes as in the ILAS data set, rather than the large divergence expected going from equator to the pole as with the ER-2 data set.

\subsection{Separation of Vortex Inside and Outside Air}

[20] The comparison between ILAS and ER-2 measurements was repeated by separating the ILAS data into inside and outside vortex measurements, while the ER-2 curves [Proffitt et al., 2003] were not separated and therefore remain unchanged. Since the vortex is only well established in winter and spring the separation was only done for these seasons. The results for winter and spring are shown in Figure 7 for the altitude bins and in Figure 8 for the potential temperature bins. In general, for the outside vortex air, a negative correlation is found at all levels 

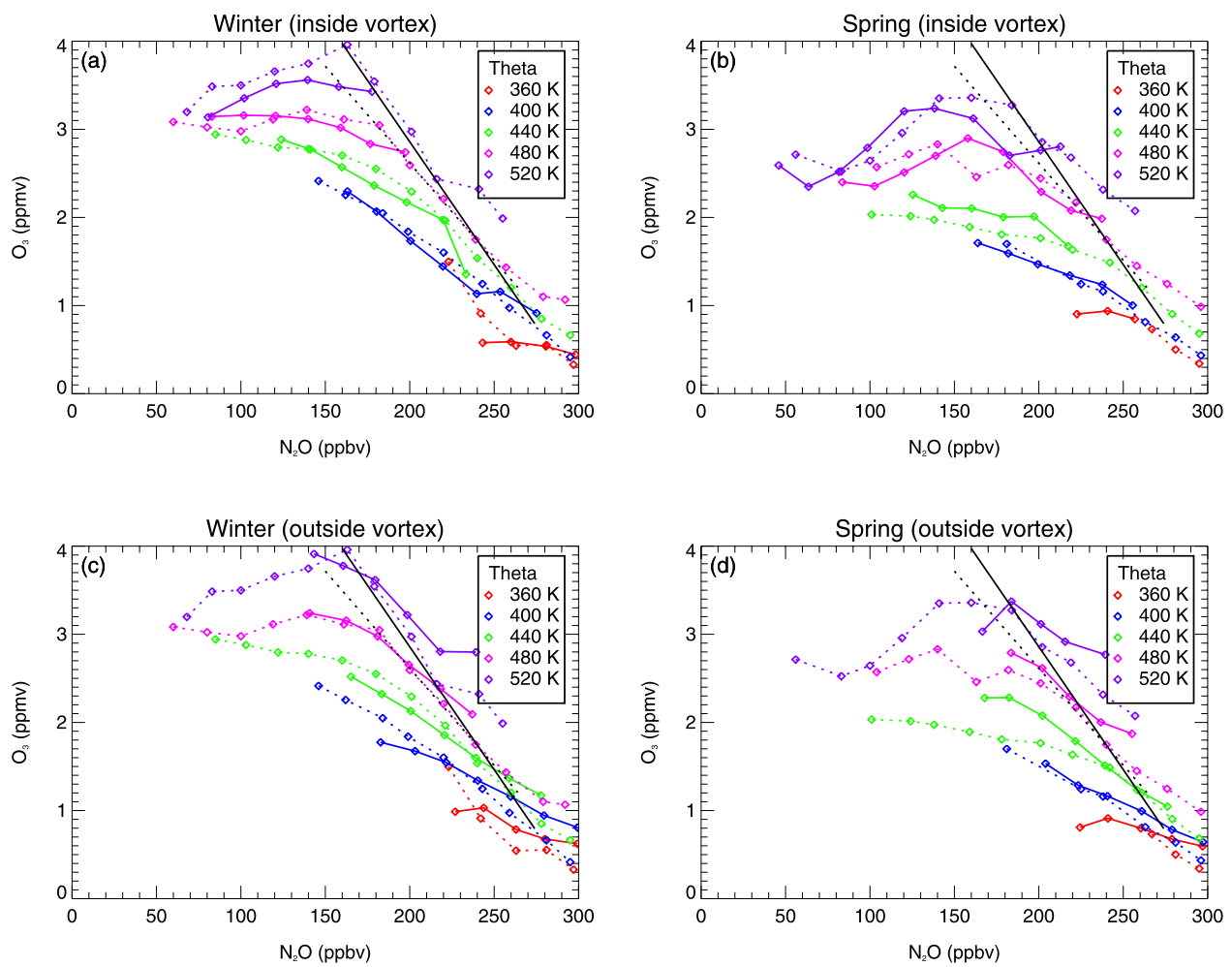

Figure 8. Seasonal averaged $\mathrm{N}_{2} \mathrm{O}$ and $\mathrm{O}_{3}$ binned by altitude for winter and spring. Comparison of ER-2 data of Proffitt et al. [2003] (dashed lines) with ILAS data (solid lines) for the Northern Hemisphere. The ILAS data are separated into inside and outside vortex air and data from above the ER-2 flight level of $\approx 20 \mathrm{~km}$ were excluded. Additionally, the midlatitude (dotted line) and vortex exterior (solid line) references from 1989 AASE ER-2 data are shown [Proffitt et al., 2003].

(Figures 7c, 7d, 8c, and 8d). Inside the vortex at 18-20 km or $480-520 \mathrm{~K}$ much lower $\mathrm{N}_{2} \mathrm{O}$ is present (around $50 \mathrm{ppbv}$ compared to around $150 \mathrm{ppbv}$ outside the vortex) and the $\mathrm{N}_{2} \mathrm{O} / \mathrm{O}_{3}$ relation is nonlinear (Figures $7 \mathrm{a}$ and $7 \mathrm{~b} ; 8 \mathrm{a}$ and $8 \mathrm{~b}$ ). This confirms both the results stated in section 4.1 and the earlier conclusions of Proffitt et al. [2003] that the slope of the curves changes owing to diabatic descent and photochemical ozone destruction occurring at the same time inside the polar vortex.

[21] The fact that for the inside vortex data points from ILAS (characterized by lower $\mathrm{N}_{2} \mathrm{O}$ values) corresponding data points from the ER-2 data are found demonstrates that the analysis of Proffitt et al. [2003] contains information from vortex measurements. Further, the agreement between the two data sets for the winter season inside the vortex is much better than for the spring season inside the vortex. In fact, the ozone loss inside the Arctic polar vortex in spring is very variable from year to year [e.g., Müller et al., 1996, 1997a; Manney et al., 2003]. Therefore a comparison of a multiyear average data with data from a particular year for vortex conditions has to be interpreted with caution.

\section{Conclusions}

[22] Proffitt et al. [2003] suggested using seasonal averages of $\mathrm{N}_{2} \mathrm{O}$ and $\mathrm{O}_{3}$ to reduce the $\mathrm{O}_{3}$ variability caused by transport processes thereby separating chemical and dynamical processes. In this study we extended the study of Proffitt et al. [2003] for the Northern Hemisphere to the
Southern Hemisphere and confirm their results for the Northern Hemisphere. Moreover, we significantly expand their results by including higher altitude data. In our study we used the ILAS data set (Version 6.0), which is particularly suited for such a study. Therefore using ILAS data allows the study of Proffitt et al. [2003] to be extended from the lower stratosphere into the middle and upper stratosphere. Additionally, due to the continuous measurements of ILAS we were able to consider monthly averages instead of seasonal averages.

[23] The families of curves resulting from the monthly averaged $\mathrm{N}_{2} \mathrm{O} / \mathrm{O}_{3}$ relationships for the Northern and Southern Hemisphere binned by altitude and potential temperature are separated and generally do not cross. This behavior was also found in the study of Proffitt et al. [2003] based on seasonal averages of high-altitude research aircraft data for the Northern Hemisphere lower stratosphere. The families of curves are better separated by binning according to potential temperature than by binning according to altitude. Owing to descent from above, the $\mathrm{O}_{3}$ maximum the curves are positively correlated above about $500 \mathrm{~K}$ and negatively correlated below. Strong diabatic descent causes a steepening of the positively correlated curves while chemical ozone loss causes a tendency toward a negative correlation, which, when sufficiently strong, results in a negative correlation. Thus the slope changes with season and is not only influenced by the intensity of descent but also by $\mathrm{O}_{3}$ photochemistry. This is, of course, a rather simplistic picture that may not completely represent all factors affecting the 
families of curves, nevertheless it is a useful approximation and is helpful in understanding the slope reversal and its seasonal change [Proffitt et al., 2003]. In both hemispheres winter ozone loss is evident and can be identified by a change in slope of the curves.

[24] The comparison of the study based on ER-2 data by Proffitt et al. [2003] and our study where ILAS data were used shows good agreement especially if the data are binned by potential temperature. Additionally, the comparison was done for the separation of the ILAS data into inside and outside the vortex air. In general, outside the vortex a negative correlation is seen at all levels. However, inside the vortex the curves are nonlinear thus confirming our previous results that descent and photochemical ozone destruction cause a change of slope.

[25] As suggested by Proffitt et al. [2003], using $\mathrm{N}_{2} \mathrm{O} / \mathrm{O}_{3}$ scatterplots reduces the variability of $\mathrm{O}_{3}$ that is due to recent latitudinal transport and therefore helps to separate transportrelated changes in $\mathrm{O}_{3}$ from photochemical changes. This separation of photochemical changes from transport-related changes is important for the understanding of $\mathrm{O}_{3}$ trends. Using the ILAS data set enabled us to confirm the results of the study of Proffitt et al. [2003] for the Northern Hemisphere and extend their analysis from the lower stratosphere to the upper stratosphere. Further, for the first time such a study was performed for the Southern Hemisphere. Our results for the Southern and Northern Hemisphere confirm the results of Tuck and Proffitt [1997] and Proffitt et al. [2003] that the polar vortex can be viewed as a flowing processor of $\mathrm{O}_{3}$ since both photochemical ozone destruction and diabatic descent occur at the same time. Moreover, our results provide a data set that may be helpful for testing atmospheric models and may be employed for tracking future changes of ozone in the northern and southern hemispheric lower and upper stratosphere.

[26] Acknowledgments. The ILAS satellite was developed by the Ministry of the Environment, Japan. The ILAS data were processed at the ILAS Data Handling Facility, National Institute for Environmental Studies (NIES), Japan. We thank the UK Met Office (UKMO) for providing their meteorological analyses and G. Bodeker for providing the PV values characterizing the vortex edge. We thank both the anonymous reviewers for their helpful comments. We also would like to thank the Japan Society for the Promotion of Science (JSPS) for supporting F. Khosrawi as a Postdoctoral Fellow at the NIES.

\section{References}

Brühl, C., and P. J. Crutzen (2000), $\mathrm{NO}_{x}$-catalyzed ozone destruction and $\mathrm{NO}_{x}$ activation at midlatitudes to high latitudes as the main cause of the spring to fall stratospheric ozone decline in the Northern Hemisphere, J. Geophys. Res., 105(D10), 12,163-12,168.

Butchart, N., and E. E. Remsberg (1986), The area of the stratospheric polar vortex as a diagnostic for tracer transport on an isentropic surface, J. Atmos. Sci., 43(13), 1319-1339.

Choi, W., S. Kim, W. B. Grant, M. Shiotani, Y. Sasano, and M. R. Schoberl (2002), Transport of methane in the stratosphere associated with the breakdown of the Antarctic polar vortex, J. Geophys. Res., 107(D24), 8209, doi:10.1029/2001JD000644.

Coy, L., E. Nash, and P. Newman (1997), Meteorology of the polar vortex: Spring 1997, Geophys. Res. Lett., 24, 2693-2696.

Crutzen, P. J., and C. Brühl (2001), Catalysis by NOx as the main cause of the spring to fall stratospheric ozone decline in the Northern Hemisphere, J. Phys. Chem. A, 105, 1579-1582.

Danielsen, E. F. (1968), Stratospheric-tropospheric exchange based on radioactivity, ozone and potential vorticity, J. Atmos. Sci., 25, 502-518.

Dobson, G. M. B., D. N. Harrison, and J. Lawrence (1973), The laminated structure of ozone in the atmosphere, Q. J. R. Meteorol. Soc., 99, 599607.
Dütsch, H. U. (1982), Ozone variability, Planet. Space Sci., 31, $1053-$ 1064.

Fahey, D. W., K. K. Kelly, S. R. Kawa, A. F. Tuck, M. Loewenstein, K. R. Chan, and L. E. Heid (1990), Observations of denitrification and dehydration in the winter polar stratosphere, Nature, 344, 321-324.

Fairlie, T. D., R. B. Pierce, J. A. Al-Saadi, W. L. Grose, J. M. Russell, M. H. Proffitt, and C. R. Webster (1999), The contribution of mixing in Lagrangian photochemical predictions of polar ozone loss over the Arctic in summer 1997, J. Geophys. Res., 104, 26,597-26,609.

Farman, J. C. (1985), Ozone photochemistry in the Antarctic stratosphere in summer, Q. J. R. Meteorol. Soc., 111, 1013-1025.

Johnston, H. S. (1975), Global ozone balance in the natural stratosphere, Rev. Geophys., 13, 637-649.

Kanzawa, H., et al. (2002), Validation and data characteristics of water vapor profiles observed by the Improved Limb Atmospheric Spectrometer (ILAS) and processed with the version 5.20 algorithm, J. Geophys. Res., 107(D24), 8217, doi:10.1029/2001JD000881. (Correction, J. Geophys. Res., 108(D4), 8218, doi:10.1029/2003JD001601, 2003.)

Kelly, K. K., et al. (1989), Dehydration in the lower Antarctic stratosphere during late winter and early spring, 1987, J. Geophys. Res., 94, 13171357.

Lait, L. R. (1994), An alternative form for potential vorticity, J. Atmos. Sci., $51,1754-1759$

Lary, D. J., M. P. Chipperfield, J. A. Pyle, W. A. Norton, and L. P. Riishojgaard (1995), Three-dimensional tracer initialization and general diagnostics using equivalent PV latitude-potential-temperature coordinates, Q. J. R. Meteorol. Soc., 121, 187-210.

London, J. (1985), The observed distribution of atmospheric ozone and its variations, in Ozone in the Free Atmosphere, edited by R. C. Whitten and S. S. Prasad, pp. 11-80, Van Nostrand Reinhold, New York.

Manney, G. L., L. Froidevaux, M. L. Santee, N. J. Livesey, J. L. Sabutis, and J. W. Waters (2003), Variability of ozone loss during Arctic winter (1991 to 2000) estimated from UARS Microwave Limb Sounder measurements, J. Geophys. Res., 108(D4), 4149, doi:10.1029/ 2002JD002634.

McIntyre, M. E. (1992), Atmospheric dynamics: Some fundamentals, with observational implications, in Proceedings of the International School of Physics "Enrico Fermi," CXV Course, edited by J. C. Gille and G. Visconti, pp. 313-386, North-Holland, New York.

McKenna, D. S., J.-U. Grooß, G. Günther, P. Konopka, R. Müller, G. Carver, and Y. Sasano (2002), A new Chemical Lagrangian Model of the Stratosphere (CLAMS): 2. Formulation of chemistry scheme and initialization, J. Geophys. Res., 107(D15), 4256, doi:10.1029/ 2000JD000113.

Müller, R., and G. Günther (2003), A generalized form of Lait's modified potential vorticity, J. Atmos. Sci., 60, 2229-2237.

Müller, R., P. J. Crutzen, J.-U. Grooß, C. Brühl, J. M. Russel III, and A. F. Tuck (1996), Chlorine activation and ozone depletion in the Arctic vortex: Observations by the Halogen Occultation Experiment on the Upper Atmosphere Research Satellite, J. Geophys. Res., 101, 12,53112,554 .

Müller, R., P. J. Crutzen, J.-U. Grooß, C. Brühl, J. M. Russell III, H. Gernandt, D. S. McKenna, and A. F. Tuck (1997a), Severe chemical ozone loss in the Arctic during the winter of 1995-96, Nature, 389, $709-712$.

Müller, R., J.-U. Grooß, D. McKenna, P. J. Crutzen, C. Brühl, J. M. Russell, and A. F. Tuck (1997b), HALOE observations of the vertical structure of chemical ozone depletion in the Arctic vortex during winter and early spring 1996-1997, Geophys. Res. Lett., 24, 2717-2720.

Müller, R., J.-U. Grooß, D. McKenna, P. J. Crutzen, C. Brühl, J. M. Russell, L. Gordley, J. Burrows, and A. F. Tuck (1999), Chemical ozone loss in the Arctic vortex in the winter 1995-1996: HALOE measurements in conjunction with other observations, Ann. Geophys., 17, 101-114.

Nakajima, H., et al. (2002), Characteristics and performance of the Improved Limb Atmospheric Spectrometer (ILAS) in orbit, J. Geophys. Res., 107(D24), 8213, doi:10.1029/2001JD001439.

Nash, E. R., P. A. Newman, J. E. Rosenfield, and M. R. Schoeberl (1996), An objective determination of the polar vortex using Ertel's potential vorticity, J. Geophys. Res., 101, 9471-9478.

Pierce, R. B., T. D. Fairlie, E. E. Remsberg, J. M. Russell, and W. L. Grose (1997), HALOE observations of the Arctic vortex during the 1997 spring: Horizontal structure in the lower stratosphere, Geophys. Res. Lett., 24, $2701-2704$

Pierce, R. B., J. A. Al-Saadi, T. D. Fairlie, J. R. Olson, R. S. Eckman, G. S. Lingenfelser, W. L. Grose, and J. M. Russell (1999), Large-scale stratospheric ozone photochemistry and transport during the POLARIS campaign, J. Geophys. Res., 104, 26,525-26,545.

Proffitt, M. H., J. J. Margitan, K. K. Kelly, M. Loewenstein, J. R. Podolske, and K. R. Chan (1990), Ozone loss in the Arctic polar vortex inferred from high altitude aircraft measurements, Nature, 347, 31-36. 
Proffitt, M. H., K. Aikin, J. J. Margitan, M. Loewenstein, J. R. Podolske, A. Weaver, K. R. Chan, H. Fast, and J. W. Elkins (1993), Ozone loss inside the northern polar vortex during the 1991-1992 winter, Science, $261,1150-1154$.

Proffitt, M. H., K. Aikin, A. F. Tuck, J. J. Margitan, C. R. Webster, G. C. Toon, and J. W. Elkins (2003), Seasonally averaged ozone and nitrous oxide in the Northern Hemisphere lower stratosphere, J. Geophys. Res., 108(D3), 4110, doi:10.1029/2002JD002657.

Russell, J. M., L. L. Gordley, J. H. Park, S. R. Drayson, A. F. Tuck, J. E. Harries, R. J. Cicerone, P. J. Crutzen, and J. E. Frederick (1993), The Halogen Occultation Experiment, J. Geophys. Res., 98, 10,77710,797 .

Sankey, D., and T. G. Sheperd (2003), Correlation of long-lived chemical species in a middle atmosphere general circulation model, J. Geophys. Res., 108(D16), 4494, doi:10.1029/2002JD002799.

Sasano, Y., M. Suzuki, T. Yokota, and H. Kanzawa (1999), Improved Limb Atmospheric Spectrometer (ILAS) for stratospheric ozone layer measurements by solar occultation technique, Geophys. Res. Lett., 26 , 197-200.

Sasano, Y., et al. (2000), ILAS observations of chemical ozone loss in the Arctic vortex during early spring 1997, Geophys. Res. Lett., 27, $213-216$.

Strahan, S. E., M. Loewenstein, and J. R. Podolske (1999), Climatology and small-scale structure of lower stratospheric $\mathrm{N}_{2} \mathrm{O}$ based on in situ observations, J. Geophys. Res., 104, 2195-2208.

Sugita, T., et al. (2002), Validation of ozone measurements from Improved Limb Atmospheric Spectrometer (ILAS), J. Geophys. Res., 107(D24), 8212, doi:10.1029/2001JD000602.
Terao, Y., Y. Sasano, H. Nakajima, H. Tanaka, and T. Yasunari (2002), Stratospheric ozone loss in the 1996/1997 Arctic winter: Evaluation based on multiple trajectory analysis for double-sounded air parcels by ILAS, J. Geophys. Res., 107(D24), 8210, doi:10.1029/2001JD000615.

Tilmes, S., R. Müller, J.-U. Grooß, D. S. McKenna, J. M. Russell, and Y. Sasano (2003), Calculation of chemical ozone loss in the Arctic winter 1996-1997 using ozone-tracer correlations: Comparison of Improved Limb Atmospheric Spectrometer (ILAS) and Halogen Occultation (HALOE) results, J. Geophys. Res., 108(D2), 4045, doi:10.1029/ 2002JD002213

Tuck, A. F., and M. H. Proffitt (1997), Comment on "On the magnitude of transport out of the Antarctic polar vortex" by Wiel M. F. Wauben et al., J. Geophys. Res., 102, 28,215-28,218.

Yokota, T., et al. (2002), Improved Limb Atmospheric Spectrometer (ILAS) data retrieval algorithm for Version 5.20 gas profile products, J. Geophys. Res., 107(D24), 8216, doi:10.1029/2001JD000628.

F. Khosrawi and H. Nakajima, Ozone Layer Research Project, National Institute for Environmental Studies, 16-2 Onogawa, Tsukuba, Ibaraki 305-8506 Japan. (f.khosrawi@fz-juelich.de; hide@nies.go.jp)

R. Müller, ICG-I, Forschungszentrum Jülich, D-52425 Jülich, Germany. (ro.mueller@fz-juelich.de)

M. H. Proffitt, Atmospheric Research and Environment Programme/ Environment Division, World Meteorological Organization (WMO), 7 bis, Avenue de la Paix, Case Postal 2300, CH-1211 Geneva, Switzerland. (mproffitt@wmo.int) 